\title{
Summary and Research Implications
}

\author{
Gabriele Doblhammer and Jordi Gumà
}

Despite considerable changes in family forms during the past decades, the influence of family on health is strong and persistent. All over Europe the elderly still live in more traditional family forms related to marriage and their family biographies are closely tied to the civil status of their partnership. On the other hand, new family forms have been emerging among the young, yet the prevalence and acceptance of these forms differs widely between societies. At a young age, the distribution of paid and unpaid work within the household is largely gendered, and in the case of families with children it is centred around the care provision for children; at old age, when paid work has ceased and income is secured by pension systems, the distribution of unpaid work is less of an issue, while the care provision for partners is at the heart of gendered family responsibilities.

Among the young and middle aged adults, where variability in health is low, little is known about new family and partnership forms, their relationship with health, and the pathways through which they act. The young population is heterogonous in terms of their ethnic background, and little is known whether the relationship between family forms and health is universal in a society or dependent on migration background and the respective values and norms. And little is known to what extent advantaged and disadvantaged family forms are universal in different welfare state regimes or whether they depend on the social and cultural context of a society.

Among the old, when different ageing trajectories result in an increasing variability in individual health, the health of the partner becomes even more important; in combination with an individual's own health there might be strong mutual

\author{
G. Doblhammer $(\square)$ \\ Institute for Sociology and Demography, University of Rostock, Rostock, Germany \\ e-mail: gabriele.doblhammer@uni-rostock.de \\ J. Gumà \\ Department of Political and Social Sciences, University Pompeu Fabra, \\ Barcelona, Spain \\ e-mail: jordi.guma@upf.edu \\ (C) The Author(s) 2018 \\ G. Doblhammer and J. Gumà (eds.), A Demographic Perspective on Gender, \\ Family and Health in Europe, https://doi.org/10.1007/978-3-319-72356-3_2
}


influences. Thus, the present family situation and abrupt changes may become more important for an individual's health when compared to the lifelong family biography. Not much is known about if or how partners advancing in age start to resemble each other more closely in terms of health and how the health of the partner influences an individual's own health. Little is known about how geographical and emotional closeness or distance of family members affects health.

In the following we summarize and discuss the main findings of this book by touching on the issues mentioned above. While all these studies explore novel aspects in the triangle of health, family, and gender, they can provide only some insight into this wide-ranging topic. We will first focus on the relationship between traditional and new family forms and health among the young, then turn to the effect of partnership and parenthood among the old, then discuss some of the possible pathways, and end with future possible research directions. We try to give an encompassing view of all studies in this book but point out that the individual authors discuss their findings and future avenues of research in much more detail.

\section{Traditional Family Forms, New Living Arrangements and Health Among the Young and Middle Aged}

In all young and middle aged populations studied, the best health is found among the married and those living together with a partner, who have two or more children. This is true for all welfare state regimes (Doblhammer and Gumà) and, in the case of Germany, for both migrant and non-migrant groups (Georges, Kreft, and Doblhammer). This health advantage is larger for women than men and it is generally the case that women's health depends on household characteristics to a larger extent than does men's health (Doblhammer and Gumà).

While for women new family forms are by and large associated with a health disadvantage, the extent of this disadvantage differs between welfare state regimes. Most of the findings described below stem from cross-sectional perspectives; in the Austrian study (Buber-Ennser and Hanappi) they become even stronger in a longitudinal perspective when union dissolution and separation are studied, which generally result in worse health.

\section{Consensual Unions and Stepfamilies}

In Austria, women living in a stepfamily where at least one partner has a pre-union child, either living in the household or not, have worse health (Buber-Ennser and Hanappi). This finding is supported by the cross-country study for selected European countries where cohabiting women (with or without children) have worse health than the married (Doblhammer and Gumà). These effects seem to be largely 
the result of financial deprivation, because the inclusion of variables indicating the ability to financially make ends meet partly or fully attenuate the observed relations. Furthermore, poor health in complex stepfamilies is particularly prevalent among people with less education and is absent among the highly educated. In addition to financial aspects, another important influence appears to be a society's value climate towards new family forms. When the value climate is indirectly measured in terms of the proportion of a certain family form, the disadvantage of new family forms is smaller (or even disappears) in societies where they are comparatively more frequent.

Concerning stepfamilies and cohabitation, similar but much weaker health tendencies exist for men, which are statistically not significant. Financial difficulties are a less important mediator, and on the contrary cohabiting men seem to be better off in financial terms. Thus, there is a strongly gendered effect of the household structure on health.

\section{Single Parents}

Single mothers have worse health than the partnered in all countries studied and this is due largely to financial difficulties. While the negative effects of consensual unions disappear in societies where they are more frequent, this is not true for single mothers (Doblhammer and Gumà). The more frequent they are, the higher the disadvantage in terms of their health. Financial difficulties or deprivation partly explain this disadvantage. Single mothers are more prevalent in the Nordic Dual-Earner welfare states, where partners usually rely on two incomes, which makes it particularly difficult for single mothers to generate sufficient household income. Another important aspect may be the lack of a partner in daily childcare and household chores, a lack of general support by friends, family and society, and the burden of increased or even sole responsibilities for the child.

\section{Living Apart Together}

Another new living arrangement is living apart together (LAT) which has been studied in the Austrian context (Buber-Ennser and Hanappi). This is the only study among the young which did not confine family to the household and in which information about partners living outside the household was available. Both men and women in a LAT relationship experience better health, but for men the effect is larger than for women and statistically significant. When it comes to health, financial factors do not seem to play an important role. 


\section{Generational Household Composition Among Migrants and Non-migrants}

While new family forms are negligible among the migrant groups studied in Germany, they differ markedly by their generational composition. Migrants from Turkey and Aussiedler, who primarily stem from countries of the former Soviet Union, more often live in a multi-generational household context than Germans (Georges, Kreft, and Doblhammer). These three groups also differ concerning their individual values, cultural norms, and their social backgrounds. Thus, one might expect differences in the effect of the household structure on individual health by migration background. The study, however, reveals (with few exceptions) a similar relationship in all three groups: individuals living in two generation households with multiple children, i.e. a couple with two or more children, have superior health compared to all other groups, and individuals living in a one generation household have the worst health. Living without a partner is negatively associated with health, and the extent of the effect is similar for all three groups. Furthermore, in all three groups women's health depends to a larger extent on the household form, but most importantly, the effect of a specific household form on health is equally gendered among migrants and native Germans. It is difficult to interpret this finding because it can imply two things. On the one hand, the social structure of German society, in the form of its welfare state, the health system, and the prevailing norms and values may simply overrule any differences in the relationship between household form and health that might result from different cultural backgrounds. On the other hand, Turkish migrants and Aussiedler in Germany, many of whom have spent extended periods in Germany, may have adopted norms and values of the majority populations with regards to family composition and health.

\section{The Relationship Between Family and Health Among the Elderly}

At young and middle ages the household composition influences women's health in particular and creates a disadvantage for all women who do not follow the traditional family norm of living in a marriage with two or more children. While similar tendencies do exist for men, the effects are much smaller. At old age this gendered response changes, with men's health becoming equally dependent on the household and family composition. Two country studies of Italy (Tomassini, Di Gessa, and Egidi) and Sweden (Doblhammer, Peters, Rizzuto, and Welmer) come to this conclusion, albeit by examining two populations with widely different welfare states, family values, and norms, and by using different health measures and study designs. In addition, a third Italian study (Giannantoni and Egidi) concludes that with advancing age the members of a household become more equal in their health outcome. 


\section{Children and Health}

One of the two Italian studies investigates the relationships between fertility and late life health in a familialistic welfare state system where the family is at the centre of care provision, cohabitation between different generations is more frequent, and gender roles are more traditional (Tomassini, Di Gessa, and Egidi). In this context, the dependency between fertility and later life health for women may be even larger than in other populations for two reasons. First, health selection into fertility might be stronger due to social pressure into marriage and fertility, leaving the "unfit" more often unmarried and/or childless. Second, the negative consequences of having a large number of children might be stronger because the care burden of rearing the children has to be mainly covered by mothers (and grandmothers). On the other hand, large family networks might reduce stress related to child rearing by distributing care work on more (family) shoulders. The selection argument also holds for men, and large numbers of children would create additional pressure on fathers to provide economic resources. However, as this study focuses on elderly women and men, one might not expect such a large difference compared to other welfare state regimes, because the childbearing period of the cohorts observed usually took place before or at the beginning of the second demographic transition, at a time when welfare states, household compositions, and gender roles did not differ to such an extent as they do today.

At a first glance the Italian study reveals similar patterns to what was previously observed in other populations. Namely, health is best for mothers with one or two children; large numbers of children are detrimental to various health domains of mothers and also, to some extent, of fathers and the relationship is generally stronger among women than men. Most interestingly, the detrimental health effect is not modified by the quantity of contacts between mothers and children. Thus close relations with adult children might not be able to buffer the negative consequences of repeated pregnancies. These results are reflected in the Swedish study (Doblhammer, Peters, Rizzuto, and Welmer) insofar that having children is definitely beneficial for men's health but not necessarily for women's health. The Swedish study is set in a welfare state system in which the state is the centre of care provision, but in which more recently the family, and in particular the partner, has become more important in providing care. Cohabitation between old and middle aged generations is not frequent, and gender roles are more equal. While the Swedish study, due to sample size, was not able to look into the relationship by number of children, it was obvious that in terms of health men profited more from fatherhood than women do from motherhood.

In Italy, the childless do not suffer from worse health, which, given that health selection into childlessness does exist, might point towards the possibility that parenthood is also associated with negative social consequences that are avoided by being childless. On the other hand, only the fittest childless individuals might have survived until old age. The Swedish study permitted a somewhat deeper insight by differentiating between being childlessness while living with a partner and being 
childless without a partner. There it was interesting to see that the childless in partnerships had the fastest deterioration of health, which might be an indication of negative health selection having taken place.

The Italian study showed that social factors are able to modify possible biological effects of fertility on late life health. First, there was no effect of closely spaced children on any of the health domains late in life, which may point towards beneficial and stress reducing effects for parents rearing children in a closely knit family environment. In addition, having a child very early in life was positive for late life health among women in Southern Italy, while it was detrimental in Northern Italy, which may be related to a higher acceptance of early and high fertility in the South. Interestingly, indicators of marital history and early childhood circumstances did not influence the relationship between fertility and health, despite being significant themselves.

\section{Partner and Health}

In the above mentioned Italian study, present marital status was more predictive of health than the marital biography, and the presently married generally had better health. While the latter result was particularly strong and significant for self-rated health and limitations, it was also a tendency for ADL, IADL, and depressive symptoms. The Swedish study further extends these findings, by showing that in terms of walking speed as an indicator of health, living in a partnership is more beneficial for men than for women; for women it can even be detrimental. For men there is a positive relationship between walking speed and the number of possible resources of help in the family: the childless without a partner have the slowest walking speed, those with children and a partner have the fastest. For women no such relationship exists: children tend to be slightly positively related to walking speed, partners have a negative influence on walking speed.

In conclusion, the two studies provide strong evidence that biological factors partly underlie the relationship between fertility and late life health, particularly among women, but that this relationship is widely responsive to the social environment. In addition, living with a partner at old age can be beneficial, which is mainly seen for men. For women, however, it can also create an additional burden due to care giving which reflects negatively on their own health. Most interestingly, these findings appear to be independent of the welfare state regime.

\section{The Effect of the Household Level on Health}

The question whether the impact of the household situation on the health of its individual members differs in a familialistic welfare state regime is taken up in a different study (Giannantoni and Egidi). In the special context of Italy, dependent 
on the health indicator used, about $15-38 \%$ of the variability in health can be attributed to joint factors at the household level. These figures fall into the range reported by other studies, which, however, deal primarily with less developed countries. Figures reported for the US are between 9 and 15\%. Most interestingly, the study reveals that the health of household members is more homogenous in small families and within couples, and that homogeneity increases with age, despite the fact that the variability in individual health increases with age. The authors attribute this increasing homogeneity not only to similar health determinants within a household, such as nutritional choices or prevention attitudes, but also to mutual influences, which they define in relation to the health outcome itself. In other words the good or poor health of one household member may influence the health outcomes of the other members. Whether this effect is stronger for men or for women cannot be answered based on the cross-sectional data the study uses, because a time reference for the deterioration of the health among partners is missing. Here, again, the Swedish study sheds some more light by showing that living in a partnership is not necessarily beneficial for the health of women, while it is definitely positive for men. Thus, as the authors of the Italian study hypothesize, the "contagion" of poor health from men to women might be stronger than from women to men. At the centre of this "contagion" is certainly the gender specific role of care provision in the context of lower life expectancy and earlier health deterioration among men. While there is strong evidence on the negative effects of the care giver burden, still more research is needed regarding to what extent this burden can be relieved by the health system in particular, the welfare state in general, as well as social attitudes in terms of formal and informal care provision. There is ample evidence that the care giver burden is particularly large when care is provided due to feelings of obligations rather than voluntarily. In addition, it is unclear to what extent the psychological effects of the poor health of a close family member exert a negative influence on the health and well-being of others independent of the burden of care giving.

\section{Pathways}

All studies in this book show that family type is correlated with social status measured, e.g. in terms of education, occupational status, and income, and that social status explains some of the differences in health by family status. However, much remains unexplained and other important pathways must exist additionally. Two pathways have been explored in detail in the individual country studies: financial difficulties and health behaviour. 


\section{Financial Difficulties}

One important factor is financial difficulties measured in terms of the ability to make ends meet. This is a very powerful indicator that explains the disadvantaged health among women living in new family forms such as stepfamilies, consensual unions with or without children, and very importantly, of single mothers (Buber-Ennser and Hanappi). It accounts for many of the significant differences between women living in new family forms and married women with children. Interestingly, this is not the case for men because accounting for the presence of financial difficulties even increases the extent of male health differences by family status. This implies that financial responsibilities partly depress the health of married fathers, less so the health of men living in other family forms.

Financial deprivation is not only an important pathway in populations where new family forms are less frequent, such as the Familialistic and Transition Post-Socialist welfare states, but also in the countries of the Dual-Earner and the General Family Support regimes (Doblhammer and Gumà). However, the types of new family forms sensitive to financial deprivation differ. In the Nordic Dual-Earner welfare states, living in a consensual union has become an alternative to marriage even when children are present. These family types do not necessarily experience financial difficulties, and while women do suffer some disadvantage in health as compared to the married, the difference is rather small. In many of the other countries, however, consensual unions are often a transitory phase to marriage with probably little difference in the health outcome, but often they are also characterised by fragile living arrangements with low household income, instable and changing partnerships, and insufficient social support from family and friends. Women living in these types of consensual unions may indeed be very similar to single mothers, who are among the most disadvantaged groups in all welfare state regimes. Despite the high labour market involvement of single mothers (the latest OECD figures show that in all welfare states their labour participation reaches or even surpasses that of married women) they have a high risk of financial deprivation mainly due to part-time employment and the foregone income of a second adult household member.

\section{Life-Style Factors}

In addition to social status and financial deprivation, life style factors turn out to be an important pathway of differences in health by family status. Among German young and middle aged adults, those married with children follow better health behaviours in terms of diet, smoking, physical activity and alcohol consumption (von der Lippe and Rattay). Some of these differences, however, appear to be mediated by social status, e.g. the healthier diet of married women and men, while others such as the higher prevalence of smoking among the divorced and widowed 
are independent of social status. Here it is interesting to note that for both genders children have a genuine effect on better diet starting with the arrival of the first child, and smoking is less prevalent among parents with two or more children independent of social status.

As mentioned previously, single never married and divorced mothers are a particularly vulnerable group with the highest odds of smoking and at-risk alcohol consumption (although they do appear to be physically more active). This group is exposed to reinforcing risk factors of poor health, starting with financial deprivation and lack of social resources and appreciation, to unhealthy behaviour.

The number and ages of children are significant modulators of these associations. Having a higher number of children and living together with pre-school children usually leads to better health behaviour. While the German study is based on cross-sectional data, this finding hints at important life-course changes in health behaviour associated with the family biography.

Healthy behaviour appears to be linked with parenthood more closely among women than men and it has been suggested that this has to do with the social roles occupied by men and women. While the partnership status per se does not have a gendered influence on health behaviour in present day Germany, it did have a gendered impact in the past. One may speculate that this shall have to do with a disappearance of specific gender roles over time, with women being strongly involved in the labour force and men becoming more involved in household chores. However, the arrival of a first, and even more often, of a second child usually results in taking up more traditional social roles leading to gendered health behaviour of parents.

\section{Biological Pathways}

While the pathways described above are of social origin, some of the studies also pointed towards biological pathways, although we were not able to test these directly. Health selection into partnership status as well as into childlessness is to some extent certainly a biological phenomenon. More important, however, is the finding that among women high fertility may go together with worse health in the long-term. In the Italian study (Tomassini, Di Gessa, and Egidi), none of the indicators included in the partnership biography could explain the increase in poor health by repeated pregnancies, and frequency of contacts with children at old age also could not account for the negative strain. The biological origin of the health disadvantage is further strengthened by the absence of strong health patterns in relation to the number of children among men. The keynote chapter on gender and health discusses hormonal and genetic foundations of health differences between men and women (Oksuzyan, Gumà, and Doblhammer). These biological foundations may also be associated with fertility histories. Still, the societal context may be able to modify possible biological pathways, as pointed out by the keynote chapter on families and health. 


\section{Future Research Directions}

Present research has widely documented the differences in health by family status between different populations at a specific point in time, different groups within population, for the young and middle aged, and the old.

The next step in understanding these differences must overcome the traditional characterization of family status by marital status, partnership status, or parenthood characteristics. Some of the studies in this book have started in this direction, but only first steps have been taken. One way to proceed further is to characterize fragile and non-fragile living arrangements. This categorization cannot only rely on the present family status but also has to include partnership and fertility biographies, in particular frequently changing and unstable partnerships as well as major disruptions such as the birth of a child, and the end of a partnership such as divorce or widowhood. The characterization of fragile family forms is of great importance among the young and middle aged where the new family forms have been emerging. However, they also need to be identified among the old, where it has probably more to do with geographical and emotional closeness or distance among family members not living in the same household.

This characterization could shed more light on the underlying pathways such as the immediate and long-lasting effects of financial deprivation, risky health behaviours, lack of social support, care obligations, etc. These pathways change over the course of family biographies, leading to periods of life with more or less positive health repercussions. These different periods may reinforce or counterbalance each other, and healthy or unhealthy behaviour during specific time periods or at specific family situations may have a particularly positive or negative outcome for immediate or long-lasting health.

When exploring sensible time periods and ages, not only the health of adult but also of child and adolescent members of a household should be investigated. This aspect was briefly touched upon in one of the keynote chapters of the book but was not taken further in the individual studies. Similar to other early-life influences, the question arises whether certain family situations do have an immediate or long-lasting effect on a young individual's health by initiating a certain pathway or by acting at a vulnerable age.

Another important step is to explore changes in health differences by family forms over time. With new family forms developing in the course of the second demographic transition and the emergence of new gender roles, the selection forces into specific family forms have also been changing and will continue to do so in future. Dependent on the social acceptance and, thus, on the social support of new family forms, one would expect a weakening (high acceptance) or strengthening (low acceptance) of the health advantage of the married (with children) with respective changes in gendered health behaviours, financial situation, and the distribution of paid and unpaid work.

In many European societies the baby boomer cohorts are among the forerunners of new family forms. They have been starting to approach young old age in recent 
years and will continue to do so in the near future. They will be the first cohorts in which new family forms at old age will become more prevalent and much may be learnt in studying their health profile in comparison with previous cohorts at the same age.

Over the last decades European societies have become more diverse due to migrant populations. These populations differ significantly in their family composition within households but also beyond the household. Earlier migrant cohorts are now approaching old age and little is known whether their relationships between family composition and health differ from those of the majority population. Other important migrant specific questions are whether family composition is related to re-migration and whether this is correlated with health, and whether life-course influences, such as age at migration, modify the relationship between family composition and health.

While working on this book it became ever more obvious that family demographers interested in the formation and dissolution of families, as well as the gendered distribution of tasks within families and demographers interested in morbidity and mortality, need to work together more closely. In order to gain a better understanding of the underlying processes in this wide-spread research area we will need to overcome the traditional boundaries in the field of demography.

But also boundaries between disciplines must be overcome to translate research findings into policy recommendations. Among others, demographers, health economists, political scientist and sociologists working on poverty and social inequality need to combine their research efforts to come up with ideas and suggestions for policies which can help battle poor health associated with certain family situations.

We close this summary of findings and ideas by observing that the relationship between health, family, and gender is a perfect example of the paradox that research leads to a better understanding, but even more, to unsolved puzzles. We hope that our contribution in the form of this book provides both new insights and new questions.

Open Access This chapter is licensed under the terms of the Creative Commons Attribution 4.0 International License (http://creativecommons.org/licenses/by/4.0/), which permits use, sharing, adaptation, distribution and reproduction in any medium or format, as long as you give appropriate credit to the original author(s) and the source, provide a link to the Creative Commons license and indicate if changes were made.

The images or other third party material in this chapter are included in the chapter's Creative Commons license, unless indicated otherwise in a credit line to the material. If material is not included in the chapter's Creative Commons license and your intended use is not permitted by statutory regulation or exceeds the permitted use, you will need to obtain permission directly from the copyright holder. 